Revista Brasileira de Agricultura Irrigada v.10, no.5, p. 943 - 951, 2016

ISSN 1982-7679 (On-line)

Fortaleza, CE, INOVAGRI - http://www.inovagri.org.br

DOI: $10.7127 /$ rbai.v10n500473

Protocolo 473.16 - 16/08/2016 Aprovado em 14/10/2016

\title{
EFEITO DE NÍVEIS DE REPOSIÇÃO DE ÁGUA NO SOLO NA CULTURA DO ARROZ DE TERRAS ALTAS
}

\author{
Marcio Koetz ${ }^{1}$, Isabela Seixo de Brito Louzada ${ }^{2}$, Edna Maria Bonfim da Silva ${ }^{1}$, Salomão \\ Lima Guimarães ${ }^{1}$
}

\section{RESUMO}

A maior limitação para o cultivo do arroz é a inadequada umidade do solo durante o seu ciclo, pois apresenta alta suscetibilidade ao estresse hídrico. Assim, objetivou-se avaliar o efeito dos níveis de reposição de água no solo sobre o crescimento, o teor de clorofila e as características produtivas do arroz em Latossolo Vermelho de Cerrado. O experimento foi conduzido em casa de vegetação em vasos com $14,5 \mathrm{dm}^{3}$ de solo. Os níveis de reposição de água foram 50 , $75,100,125$ e 150\% do volume de reposição à capacidade de campo, com cinco repetições cada, monitoradas por três tensiômetros instaladas no tratamento com 100 \% da reposição de água. Os resultados foram submetidos à análise de variância e regressão a $5 \%$ de probabilidade. A cultura do arroz tem seu melhor desenvolvimento e produção com os níveis de reposição de água superiores ao tratamento de referência (100\%).

Palavras-chave: Oriza sativa, casa de vegetação, tensiômetro.

\section{EFFECT OF WATER REPLACEMENT LEVELS IN THE SOIL IN UPLAND RICE CULTIVATION}

\begin{abstract}
The biggest limitation for rice cultivation is inadequate soil moisture during its cycle, because of its high susceptibility to water stress. The objective was to evaluate the effect of water replacement levels in the soil on the growth, chlorophyll content and yield characteristics of rice (BRS Monarch) in the Cerrado Oxisol. The experiment was conducted in a greenhouse in pots with $14.5 \mathrm{dm}^{3}$ of soil. Water replacement levels were $50,75,100,125$ and $150 \%$ of the volume replacement to field capacity with five repetitions each, monitored for three tensiometers installed in treating $100 \%$ of makeup water. The results were submitted to analysis of variance and regression at 5\% probability. The culture of rice has best

\footnotetext{
${ }^{1}$ Docente, Instituto de Ciências Agrárias e Tecnológicas/UFMT, Rondonópolis, MT, Rodovia RondonópolisGuiratinga, Km 06, Bairro Sagrada Família, Cep: 78735-901, e-mails: marciokoetz@yahoo.com.br; embonfim@hotmail.com; slguimaraes@ hotmail.com

${ }^{2}$ Engenheira Agrícola e Ambiental, Mestre em Agronomia pela UNESP, Fazenda Lageado Portaria I: Rua José Barbosa de Barros, nº 1780, Portaria II: Rodovia Alcides Soares, Km 3, CEP: 18.610 307, Botucatu, SP, e-mail: isabelasblouzada@ hotmail.com
} 
development and production with water replacement levels above the reference treatment $(100 \%)$.

Keywords: Oriza sativa, greenhouse, tensiometer

\section{INTRODUÇÃO}

$\mathrm{O}$ arroz é um dos cereais mais consumidos do mundo. Depois do milho e do trigo, o arroz é o cereal mais produzido do mundo, e com maior concentração em países asiáticos, com destaque para a China e a Índia. A China é o maior produtor mundial com 144 milhões de toneladas e o Brasil é o nono com estimativa de 16,5 milhões de toneladas para a safra 2014/2015 (CONAB, 2014).

No Brasil, o Rio Grande do Sul é o maior produtor de arroz (CONAB, 2013), contudo, o sistema de produção de arroz de terras altas é o mais difundido territorialmente com produção em estados como Mato Grosso, Goiás, Minas Gerais e São Paulo (FORNASIERI FILHO; FORNASIERI, 2006). Pesquisas estão sendo realizadas para proporcionar a presença da cultura em sistemas de produção de grãos nas regiões no Cerrado, sendo que a produtividade de arroz de sequeiro na região Centro-Oeste tem variado ao longo dos anos, em função das condições climáticas.

De acordo com GUIMARÃES et al. (2011), as plantas de arroz reagem ao estresse hídrico apresentando reduções na altura das plantas, produção de biomassa, aborto de perfilhos e também no atraso do desenvolvimento reprodutivo. Para que ocorra a estabilidade da produção, além do aumento da produtividade de grãos no ecossistema de terras altas, a irrigação é uma alternativa para minimizar as perdas na cultura do arroz.

Um parâmetro que permite estabelecer o momento correto da irrigação, bem como estimar a quantidade de água a ser aplicada a cada irrigação, é a tensão-limite de água no solo, que pode variar com o estádio de desenvolvimento das plantas (MAROUELLI et al., 1996). O manejo correto da irrigação pode ser realizado com auxilio de tensiômetros, que consistem de uma cápsula porosa ligada a um tubo que a conecta a um medidor de tensão (vacuômetro) que indica a força com que a água está retida no solo (MEDEIROS et al., 2013).

A irrigação como tecnologia de produção, apresenta-se como uma das principais ferramentas aplicada a garantia e ao preço de produção, principalmente quando em localidades de temperatura elevada e baixo índice pluviométrico. No entanto, faz-se necessário avaliar a real disposição de água versos ganho produtivo, a fim de contribuir com a análise de viabilidade de produção irrigada da cultura (VELA et al., 2013).

Dessa forma, objetivou-se avaliar a resposta da cultura do arroz de sequeiro, submetido a níveis de reposição de água no solo.

\section{MATERIAL E MÉTODOS}

$\mathrm{O}$ experimento foi conduzido em casa de vegetação no período de setembro de 2012 a janeiro de 2013, estando localizado a $16^{\circ}$ 28' 00' Sul e 50 $34^{\circ}$ ' $00^{\prime}$ ' Norte em altitude de $284 \mathrm{~m}$. O solo utilizado no experimento foi o Latossolo Vermelho, cuja caracterização química e granulométrica foi realizada em laboratório de acordo com a EMBRAPA (2013), coletado em área sob vegetação de Cerrado camada de 0 a $20 \mathrm{~cm}$ e peneirado em malha de $2 \mathrm{~mm}$, sendo posteriormente incubado com calcário dolomítico $(\mathrm{PRNT}=$ $80,3 \%$ ), elevando-se a saturação por bases para $45 \%$ e mantendo a umidade a $80 \%$ da capacidade máxima de retenção de água no solo.

Para a caracterização química foram obtidos os seguintes valores: $\mathrm{pH}$ em $\mathrm{CaCl}_{2}=$ 4,1; M.O. $=19,7 \mathrm{~g} \mathrm{dm}^{-3} ; \mathrm{P}=1,1 \mathrm{mg} \mathrm{dm}^{-3} ; \mathrm{K}$ $=47,0 \mathrm{mg} \mathrm{dm}^{-3} ; \mathrm{Ca}=0,2$ cmolc dm${ }^{-3} ; \mathrm{Mg}=$ $0,1 \mathrm{dm}^{-3} ; \mathrm{Al}=1,0 \mathrm{cmolc} \mathrm{dm}^{-3} ; \mathrm{V}=6,9 \%$, e para as características granulométricas do 
solo: areia $=575 \mathrm{~g} \mathrm{~kg}^{-1}$; argila $=375 \mathrm{~g} \mathrm{~kg}^{-1}$; silte $=50 \mathrm{~g} \mathrm{~kg}^{-1}$.

Cada unidade experimental foi constituída por um vaso de $14,5 \mathrm{dm}^{3}$, sendo cinco plantas cultivadas em cada vaso. O tratamento consistiu em cinco níveis de reposição de água no solo $(50,75,100,125$ e $150 \%$ ), com cinco repetições cada, sendo o delineamento inteiramente casualizado, monitorados por três tensiômetros instalados a $12 \mathrm{~cm}$ de profundidade, nos níveis de reposição de $100 \%$.

Foram feitas as adubações fosfatada $\left(\mathrm{P}_{2} \mathrm{O}_{5}\right)$ e potássica $\left(\mathrm{K}_{2} \mathrm{O}\right)$ nas doses de $200 \mathrm{mg}$ $\mathrm{dm}^{-3}$ (superfosfato simples) e de $80 \mathrm{mg} \mathrm{dm}^{-3}$ (cloreto de potássio), respectivamente. A recomendação para o nitrogênio foi de 150 $\mathrm{mg} \mathrm{dm}{ }^{-3}$, sendo dividida em três aplicações, realizadas aos 15,30 e 45 dias após a semeadura, na forma de ureia.

Durante todo o período experimental a umidade do solo foi monitorada por tensiômetros, instalados a $0,10 \mathrm{~m}$ de profundidade nos tratamentos com $100 \%$ de reposição de água (dose de referência). Com a utilização do modelo proposto por GENUCHTEN (1980) gerou-se a equação 1 que descreve o comportamento da umidade do solo em função da tensão.

$$
\theta=\frac{0,468}{\left[1+(0,057 \psi)^{0,3545}\right]^{0,5724}}
$$

em que:

$\theta$ - umidade atual com base em volume $\left(\mathrm{cm}^{3} \mathrm{~cm}^{-3}\right)$;

$\Psi$ - tensão de água no solo $(\mathrm{kPa})$.

A partir da equação e dos valores observados e com o auxílio do aplicativo Soil Water Retention Curve, foi gerada a curva de retenção de água no solo para a camada em estudo

(Figura

$1)$.

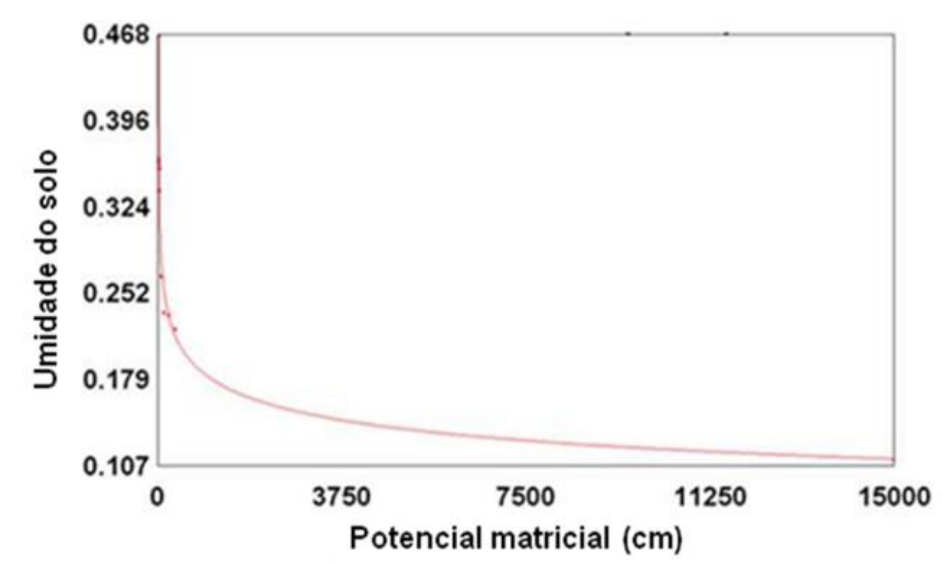

Figura 1. Curva de retenção de água no solo, gerada pelo programa Soil-Water-Retention-Curve (versão $3.0)$.

A umidade volumétrica na capacidade de campo foi determinada substituindo a tensão de água no solo na Equação 1 por 7 $\mathrm{kPa}$. Para a determinação da umidade de saturação e residual considerou-se as umidades correspondentes as tensões de 2 e $1500 \mathrm{kPa}$, respectivamente.

A leitura das tensões foram realizadas diariamente às 9 horas por meio de um tensímetro digital e o momento de irrigar foi definido quando a tensão média obtida dos quatro tensiômetros atingia o valor próximo a $25 \mathrm{kPa}$.

Para o experimento, com a capacidade de campo definida e com a umidade atual $(\theta$ atual) obtida nos tensiômetros no momento da leitura, calculou-se o volume de água necessário para elevar o solo à capacidade de campo de acordo com a equação 2 .

$$
\text { Vol }=\left(\theta_{c c}-\theta_{\text {atual }}\right) 7000
$$


em que:

$\theta$ cc - umidade na capacidade de campo $\left(\mathrm{cm}^{3} \mathrm{~cm}^{-3}\right)$; $\left.\mathrm{cm}^{-3}\right)$;

$\theta$ atual - umidade atual do solo $\left(\mathrm{cm}^{3}\right.$

Vol-volume de água $\left(\mathrm{cm}^{3}\right)$.

Inicialmente todos os tratamentos foram irrigados com a mesma lâmina de água para garantir o estabelecimento das plantas. Após 15 dias do plantio, iniciou-se a aplicação de níveis de reposição de água no solo, estabelecidos de acordo com os percentuais relativos a cada tratamento. Ao final do experimento, a média de irrigações durante o intervalo experimental foi de 1,8 dias. O tratamento com o nível de reposição de água no solo de $150 \%$, recebeu o maior volume de água aplicado (Tabela 1).

Tabela 1. Volume de água aplicado para os diferentes níveis de reposição.

\begin{tabular}{cc}
\hline $\begin{array}{c}\text { Níveis de reposição de água } \\
(\mathbf{\%})\end{array}$ & $\begin{array}{c}\text { Volume de água aplicado } \\
(\mathbf{L})\end{array}$ \\
\hline 50 & 24,32 \\
75 & 36,48 \\
100 & 48,65 \\
125 & 60,81 \\
150 & 72,97 \\
\hline
\end{tabular}

A colheita ocorreu aos 112 dias após a semeadura. Em seguida foi realizada a trilha, secagem à sombra e a limpeza do material, separando-se a palha e os grãos chocos manualmente. Em seguida determinou-se a massa seca dos grãos colhidos.

As avaliações foram realizadas aos 75 e 108 dias após emergência da planta (DAE). Aos 75 DAE foram avaliadas o número de folhas e leitura SPAD e aos 108 DAE, a altura de planta, número de panículas e massa seca de grãos.

$\mathrm{O}$ teor de clorofila foi determinado com o auxílio de um clorofilog portátil Falker CFL 1030. Para a determinação da altura da planta, foi utilizada uma régua. A massa seca de grãos foi obtida com a pesagem em balança semi analítica e os resultados foram expressos em gramas. Para a determinação da massa de grãos, estes foram colocados em sacos de papel e levadas a estufa de circulação de ar forçada à temperatura de $65^{\circ} \mathrm{C}$, até atingir massa constante, obtendo os resultados em gramas.

Os dados foram submetidos à análise a variância com a realização do teste $\mathrm{F}$ e posteriormente a regressão, ambas a 5\% de probabilidade, por meio do programa estatístico SISVAR 5.3 (FERREIRA, 2008).

\section{RESULTADOS E DISCUSSÕES}

Para o número de folhas houve ajuste a modelo quadrático de regressão nos níveis de reposição de água.

$\mathrm{O}$ maior número de folhas $(161,86)$ foi observado na reposição de água de $130,26 \%$ da capacidade de campo, com um incremento de $71,25 \%$ de número de folhas comparado ao nível de reposição de água de $50 \%$ (Figura 2). 


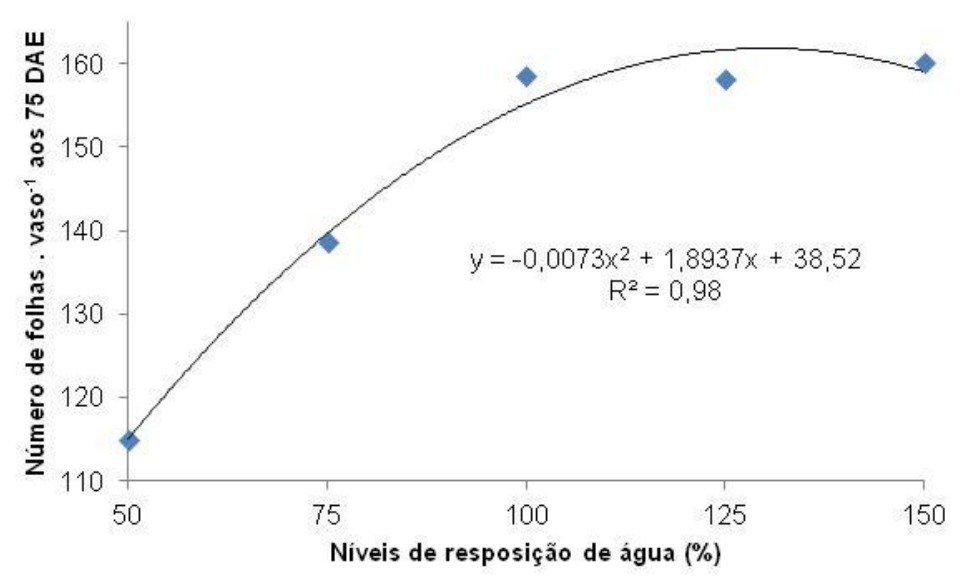

Figura 2. Número de folhas de plantas de arroz submetido a níveis de reposição de água no solo.

Segundo GUIMARÃES et al. (2011), as plantas de arroz também reagem ao estresse hídrico com reduções na altura das plantas, produção de biomassa, aborto de perfilhos e no atraso do desenvolvimento reprodutivo.

De acordo com DIAS (2008) o déficit hídrico limita o número de folhas da planta, corroborando com os resultados obtidos neste experimento, onde a menor quantidade de folhas foi observado nos menores níveis de reposição de água no solo.

Para altura de plantas houve um incremento de $30,51 \%$ quando comparado o nível máximo de reposição de água no solo (150\%) com o nível mínimo (50\%), sendo representado pelo modelo linear de regressão (Figura

$3)$.

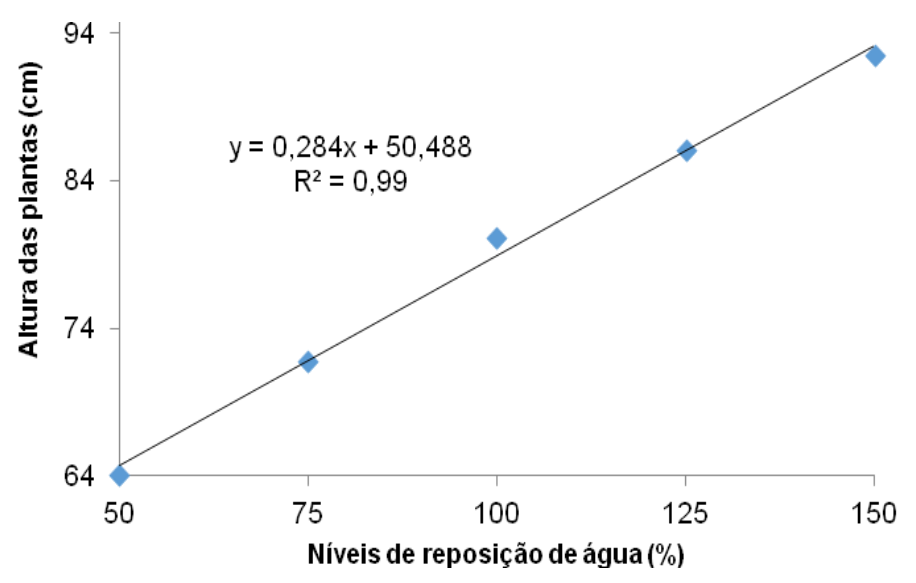

Figura 3. Altura de plantas de arroz submetido a níveis de reposição de água no solo.

Os resultados obtidos por ARF et al. (2001) com arroz irrigado por aspersão em um ano com ocorrência de veranicos, mostraram que o tratamento sem irrigação apresentou a menor altura de plantas, e na maior lâmina, o maior desenvolvimento das plantas, concordando com CRUCIOL et al. (2003b), no qual ao estudarem o efeito de lâminas de água de irrigação sobre a fenologia do arroz, observaram que a diminuição na disponibilidade de água reduziu a altura da planta, conferindo $15 \mathrm{~cm}$ de diferença entre o cultivo de sequeiro e a maior lâmina de irrigação.

TERRA et al. (2013) estudando a tolerância de linhagens de arroz de terras altas submetidas a estresse hídrico verificaram a redução na altura de plantas de $133 \mathrm{~cm}$ para 
$119 \mathrm{~cm}$ quando comparado plantas sem estresse hídrico com plantas submetidas ao estresse.

SILVA (2012) observou altura de plantas de arroz de $93 \mathrm{~cm}$ e $86 \mathrm{~cm}$ nos tratamentos com reposição de $100 \%$ da evapotranspiração $\quad$ e $\quad 50 \% \quad$ da evapotranspiração respectivamente, no genótipo de arroz Carreon.
O número de panículas foi influenciado significativamente pelos níveis dereposição de água (Figura 4), sendo representado por um modelo quadrático de regressão, onde o maior número de panículas $(35,36)$ foi observado no nível de reposição de água de $130,62 \%$ da capacidade de campo, que comparado ao menor nível de irrigação $(50 \%)$, teve um incremento de $90,05 \%$ (Figura

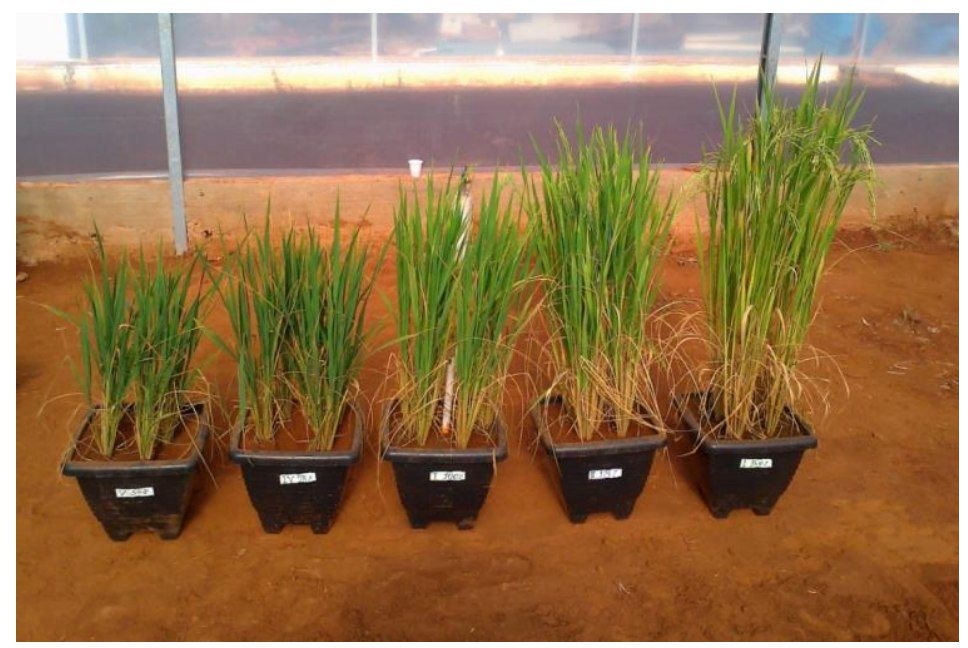

Figura 4. Curva de crescimento do arroz irrigado com os diferentes níveis de reposição de água $(50,75,100$, 125 e 150\%, da esquerda para à direita), aos 86 dias após a emergência.

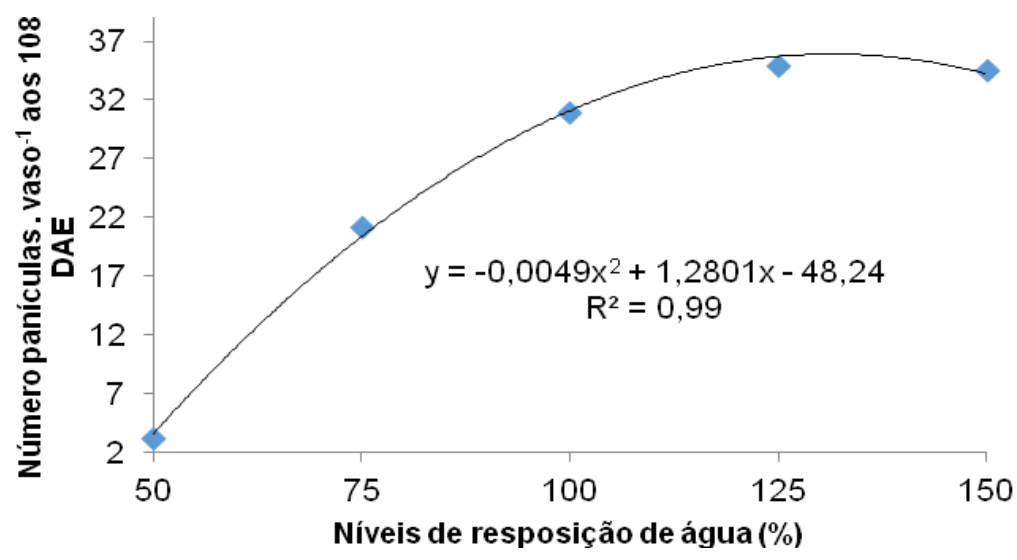

Figura 5. Número de panículas de plantas de arroz submetido a níveis de reposição de água no solo.

Segundo MOURA (2010), a deficiência hídrica afeta o número de panículas. Isso pôde ser verificado neste trabalho, com o menor número de panículas para o menor nível de reposição de água. Para CRUSCIOL et al. (2006) a ocorrência de deficiência hídrica durante o momento da passagem da fase vegetativa à fase reprodutiva reduz o número de panículas por área, pois a deficiência hídrica leva a dormência às gemas axilares (FORNASIERI FILHO \& FORNASIERI,1993), inibindo a formação de novas panículas.

Diferenças significativas para a massa seca de grãos foram observadas para os níveis de reposição de água no solo (Figura 6). 


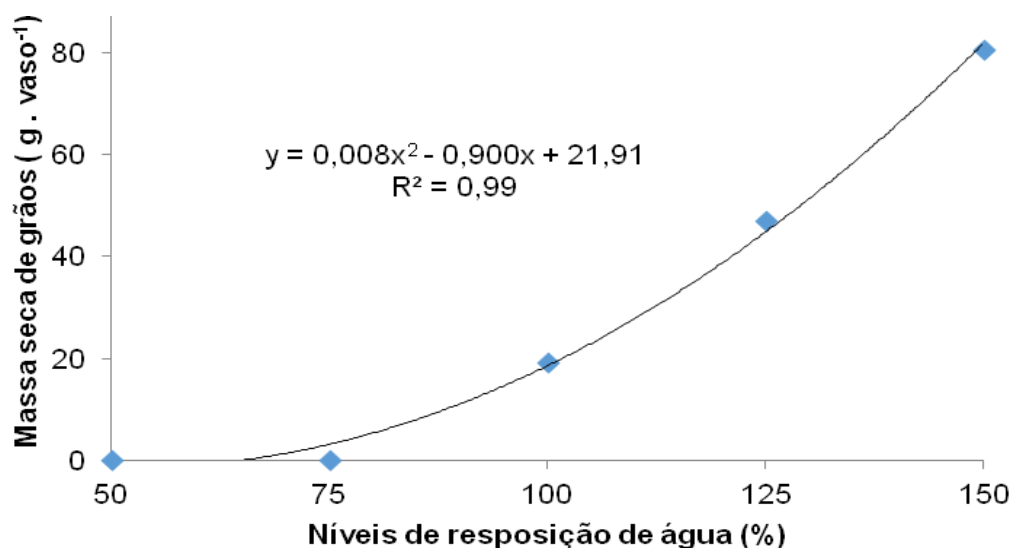

Figura 6. Massa seca de grãos de plantas de arroz submetido a níveis de reposição de água no solo.

A variável massa seca de grãos ajustouse ao modelo quadrático de regressão, com a máxima produção $\left(71,1 \mathrm{~g}\right.$ vaso $\left.^{-1}\right)$ observada no nível de reposição de água de $150 \%$ da capacidade de campo, (maior nível do intervalo experimental), sendo que o menor nível de reposição não teve produção de grãos.

O decréscimo da massa de grãos em função da disponibilidade hídrica no solo também foram observados por SURIYAN et al. (2010).

Apesar da maior produtividade ter sido obtido com o maior nível de reposição de água no solo, verificou-se que neste nível de reposição as plantas tiveram alto desenvolvimento vegetativo, com acamamento de plantas.

De acordo com a Figura 7, constatouse que o índice de clorofila foi reduzido com o aumento dos níveis de reposição de água no solo, observando-se um modelo linear de regressão, com decréscimo de 31,47\%, comparando o maior nível reposição de água $(150 \%)$ com o menor (50\%). Em estudo do efeito de déficit hídrico transiente e doses crescentes de boro sobre a fertilidade de gemas de videira cv. Itália, MELLO \& RIBEIRO (2011) também verificaram que o índice relativo de clorofila aumentou linearmente com o acréscimo das tensões de água no solo, ou seja, o aumento do déficit hídrico.

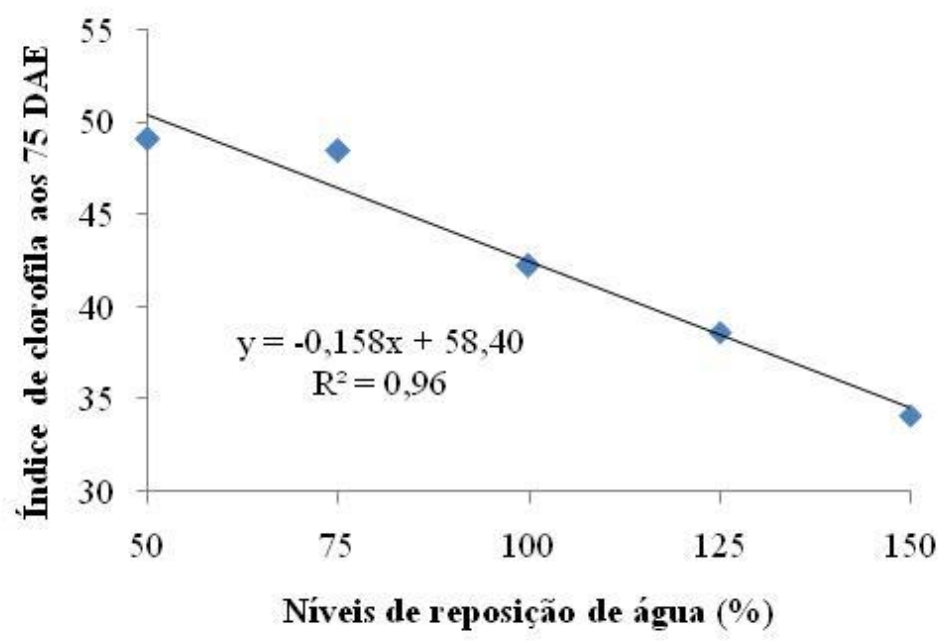

Figura 7. Índice de clorofila de plantas de arroz submetido a níveis de reposição de água no solo. 


\section{CONCLUSÕES}

A variedade de arroz BRS Monarca cultivado em solo Latossolo Vermelho do Cerrado apresenta alta susceptibilidade ao estresse hídrico.

A cultura do arroz apresenta seu melhor desenvolvimento e produção com os níveis de reposição de água superiores ao nível de reposição de água no solo de $100 \%$.

\section{REFERÊNCIAS}

ARF, O.; RODRIGUES, R.A.F.; SÁ, E.; CRUSCIOL, C.A.C. Resposta de cultivares de arroz de sequeiro ao preparo do solo e à irrigação por aspersão. Pesquisa Agropecuária Brasileira. Brasília, v.36. n. 6. p.871-879, 2001.

COMPANHIA NACIONAL DE ABASTECIMENTO - CONAB. Acompanhamento da safra brasileira: grãos, safra 2012/13 - Nono Levantamento. Junho, 2013. 30p. Brasília. Disponível em: <http:// http://www.conab.gov.br/OlalaCMS/uploads/ arquivos/13_06_06_09_09_27_boletim_graos _-_junho_2013.pdf> Acesso em: 20 julho 2016.

COMPANHIA NACIONAL DE ABASTECIMENTO - CONAB. Acompanhamento da safra brasileira de grãos. v.1- safra 2013/2014, n.12. Décimo Segundo Levantamento, Brasília, p. 1-127. Disponível em: $<\mathrm{http}: / /$ http://www.conab.gov.br/OlalaCMS/uploads/ arquivos/14_09_10_14_35_09_boletim_graos _setembro_2014.pdf> Acesso em: 20 julho 2016.

CRUSCIOL, C.A.C.; ARF, O.; SORATTO, R.P.; RODRIGUES, R.A.F.; MACHADO, J.R. Produtividade do arroz de terras altas em função de lâminas de água e da adubação mineral. Revista Científica, v.31. n.1. p.189200, 2003b.
CRUSCIOL, C. A. C.; SORATTO, R.P.; ARF, O.; MATEUS, G.P. Yield of upland rice cultivars in rainfed and sprinkler-irrigated systems in the Cerrado region of Brazil. Australian Journal of Experimental Agriculture, Collingwood, v. 46, n. 11, p. 1515-1520, 2006.

DIAS, L. B. Água nas plantas. Monografia (Graduação) - Universidade Federal de Lavras, Lavras, 2008. 50p.

EMBRAPA - EMPRESA BRASILEIRA DE PESQUISA AGROPECUÁRIA (BRASIL). Sistema brasileiro de classificação de solo. 3 ed. rev. ampl. Brasília, DF: Embrapa, 2013, $353 p$.

FERREIRA, D. F. SISVAR: um programa para análises e ensino de estatística. Revista Symposium, Lavras, v.6, p.36-41, 2008.

FORNASIERI FILHO, D.; FORNASIERI, J.L. Manual da cultura do arroz. Jaboticabal:FUNEP, 1993. 221 p.

FORNASIERI FILHO, D.; FORNASIERI, J. L. Manual da cultura do arroz. Funep, 2006, 589 p.

GUIMARÃES, C. M.; STONE, L.F.; OLIVEIRA， J.P.; RANGEL， P.H.N.; RODRUIGUES, C.A.P. Sistema radicular do arroz de terras altas sob deficiência hídrica. Pesquisa Agropecuária Tropical, Goiânia, v. 41, n. 1, p. 126-134, 2011. 71p.

MAROUELLI, W. A.; SILVA, W. L. C.; SILVA, H. R. Manejo da irrigação em hortaliças. Brasília: Embrapa - SPI /Embrapa - CNPH, 1996. 72p.

MEDEIROS, S. de; REIS, C. F.; SANTOS JÚNIOR, J. A.; HLEIN, M. R.; RIVEIRO, M. D.; SZEKUT, F. D.; SANTOS, D. B. dos. Manejo de irrigação utilizando o tensiômetro. Campina Grande/PB: INSA. Cartilha. 6 p. 2013. 
MELO, J. S. de; RIBEIRO, V. G. Efeito de déficit hídrico transiente e doses crescentes de boro sobre a fertilidade de gemas de videira cv. Itálica. Revista Brasileira de Fruticultura, Jaboticabal - SP, v. 33, n. 2, p. 482-490, 2011.

MOURA, R. S. Lâminas de água, inoculação de sementes com Azospirillum brasilense e doses de nitrogênio em arroz de terras altas. Ilha Solteira: Unesp, 2010.

SILVA, A. C. L. Alterações bioquímicas, morfofisiológicas e produtivas em genótipos de arroz em condições de deficiência hídrica. 92f. Dissertação (Mestre em Agronomia) - Faculdade de Ciências Agronômicas da UNESP. Botucatu, 2012.

SURIYAN, C., S. YO YAMGWECH AND K. SUPAIBULNEATANA. Water deficit stres in the productive stage of four indica rice (Oryza sativa L.) genotypes. Pakistan Journal of Botany, v. 42, n.5. 387p. 2010.

TERRA, T. G. R.; LEAL, T. C. A. B.; BORÉM, A.; RANGEL, P. H. N. Tolerância de linhagens de arroz de terras altas à seca. Pesquisa Agropecuária Tropical, Goiânia, v. 43, n. 2, p. 201-208. 2013.

VAN GENUCHTEN, M.T. A closed-form equation for predicting the hydraulic conductivity of unsaturated soils. Soil Science Society of American Journal, Madison, v. 44, n.1, p. 898-982, 1980.

VELA, R. H. N.; DALLACORT, R.; DALCHIAVON, F. C.; ARAUJO, D. V.; BARBIERI, J. D.; KOLLING, E. M. Lâminas de irrigação na cultura do arroz de terras altas, no médio norte do estado de Mato Grosso. ENCICLOPÉDIA BIOSFERA, Centro Científico Conhecer - Goiânia, v.9, n.17; p. 2013. 